\title{
Modeling of the virtual system of control of contrailer transportation in the information- economic space
}

\author{
Valery Zubkov ${ }^{1 *}$ and Nina Sirina ${ }^{2}$ \\ ${ }^{1}$ Federal Freight Company, Kuibysheva Street, 44, letter D, Yekaterinburg, 620026, Russia \\ ${ }^{2}$ Ural State University of Railway Transport (USURT), Kolmogorova Street, 66, 620034, \\ Yekaterinburg, Russia
}

\begin{abstract}
In the present work, the main attention is focused on research and search for the most rational, economically justified way of developing the potential of the railway industry in the field of interaction of several modes of transport in the organization and management of correspondence of piggyback traffic. The concept, which is based on the evaluation of possibilities of future subjects of the transport and logistics process to integrate into a single information field of the transport system. The information model of the system for the management of contrailer traffic in the information and economic space is considered. The stratum of cognitive subsystem in the presented virtual system allows transforming and structuring the processes of monitoring, analysis, accounting and storage of correspondence of transport infrastructure of supposed production facilities, railway stations and loading and unloading sites for their compliance with the requirements for the organization of contrailer transportation correspondence. The information subsystem's stratum reflects the functions of accounting and recording the impact of the subjects of transportation on the compliance with the technological process in all its life cycles. The application subsystem stratum reflects the process of making optimal decisions, formation of management teams. The difference of virtual control system consists in intellectual architecture, namely cognitive subsystem, which forms knowledge about unified information system and operational and technological management on the basis of above mentioned information data. Knowledge generation is based on the results of processing of system state data coming from system agents and integrators.
\end{abstract}

\section{Introduction}

The transport system in many countries is the main and most important component of the production and socio-economic systems. The pace of development of industrial and transport complexes as a whole creates conditions for economic growth of national production and improvement of living standards.

\footnotetext{
*Corresponding author: zubkovvv1973@gmail.com
} 
The existing unified transport system of the Russian Federation does not fully reflect the interests of consumers of transport services in the field of interaction of modes of transport when performing a single technological process of delivery of goods to the final recipient. As the analysis of the existing mixed cargo transportation shows, there is an obvious deficit of the public infrastructure of the automobile industry, namely, the configuration of the automobile communications network at the federal level has a radial structure with an insufficient number of connecting and chord roads, which leads to significant overruns of vehicles and, as a consequence, to an increase in the cost of cargo transportation. Most of the roads are characterized by poor road surface maintenance and low level of road transport and roadside service. High length of freight transport routes and their location in different climatic zones have an unfavorable impact on the quality of vehicle operation, which requires the use of more expensive fuels, lubricants, tires, electrical equipment adapted to low negative temperatures. Also negative impact on the transport and production process of delivery of goods in mixed traffic occurs due to the lack of contact schedules of interaction of transport (road and rail), the lack of integrated information management systems and a single transport information space between these modes of transport and loading and unloading terminals, which increases the downtime of railway rolling stock and vehicles in the places of cargo transshipment and, as a result, leads to higher costs [1].

In existing conditions, for the transport system of Russia the search of rational and economically grounded way of development of potential of the railway branch in the field of interaction of several types of transport is actual and perspective. One of such ways is the organization and management of correspondence of piggyback transport. This type of intermodal transportation creates conditions for the development of through transport and production processes, as the unified technology of cargo delivery presupposes continuity of the cargo transportation process at all its stage [2].

When organizing contrailer shipments of goods, reliability and safety, efficiency and environmental friendliness of railway transport with maneuverability and mobility of road transport are combined.

Counter-trailer transportation is successfully implemented in the USA and European countries. The world experience in organizing contrailer transportation is diverse. In the world practice, such technologies of contrailer operation as: "CargoBeamer", "Megaswing", "Modalohr", "Running Highway" and others. These technologies differ from each other in the way railway rolling stock and motor vehicles are used, the methods and speeds used, the equipment and functionality of transport terminals[3]. The listed counterflow technologies have their strengths and weaknesses. Each of them has developed in its own country in its own economic, geographical, technological conditions and to satisfy specific consumers of transport services[3,4].

Thus, taking into account the conducted researches and the accumulated world experience, important prerequisites for the development of piggyback cargo transportation in Russia have been determined:

- high cargo tension on the highways, especially on the directions of export and import cargo transportation;

- difficult climatic conditions and seasonal restrictions on road freight transport in many regions of the country;

- developed transport infrastructure for the railway industry and loading and unloading terminals;

- perfect information infrastructure of the railway transport system, availability of corporate information systems for managing transport and production processes;

- the global trend towards environmentally sustainable modes of transport;

- intensive development of the international transport and logistics services market;

- formation of modern world transport and logistics infrastructure. 
Despite the existence of an extensive list of prerequisites, counter-translair cargo transportation in Russia is at the stage of development. The main perspective for development of such intermodal cargo transportation is integration into the world transport and information space and improvement of the transit potential of the country. This perspective can be realized through the coordinated work of rail and road transport, the creation of integrated information systems for the management of transport and logistics processes in a single transport information space and the improvement of progressive ways and types of transportation of goods [5].

\section{Framework and methods of building the system}

The paper considers one of the ways to develop the potential of the railway industry in the area of interaction of modes of transport in the organization and management of correspondence of piggyback transportation. The concept of the method is based on the evaluation of the possibilities of the future subjects of the transport and logistics process to participate in this freight transportation and to integrate it into the unified information field of the world transport system [6].

The authors have developed the information model of the system for the management of the freight dispatches in the information and economic space "Automated system for the management of the complex transport service in the segment of the freight dispatches". (ASM ITS CTS).

The information model of system of ASM ITS CTS is intended for functioning in uniform transport and information space on a platform of a global database of the information data and electronic systems of the standard and reference information. Exchange of the information data occurs on the basis of the confirmed regulations [7]. Figure 1 shows the functional scheme of the information model.

As can be seen in Fig. 1, the information model ASM ITS CTS is implementing automation:

- taking into account the technical, technological and information equipment of railway stations, production enterprises and sites, terminals and cargo transshipment points with an assessment of their capabilities to forecast and plan contrailer transportation on transport routes and directions;

- accounting and ranking of conformity of technical capacities of railway stations, production enterprises and platforms, terminals and cargo transshipment points, as well as the needs in their retrofitting for the organization of counter-transit consignments;

- transport and production process at transport and logistics terminals, with assessment of reasons for failure or untimely performance of loading and unloading operations;

- control of contrailer cargo traffic, accounting and registration of fulfillment of graphical standard of contrailer road trains traffic;

- taking into account the influence of the subjects of transportation on the fulfillment of the technological norms at the whole stage of the counterreiler cargo delivery;

- execution of an application for the organization of the contreiler transportation in the electronic form approved by the regulations;

- calculation of the cost of transportation and term of cargo delivery;

- $\quad$ search for normative-reference electronic documentation regulating the transport and production process of counter-reyler transportation on transport routes and directions. 




Fig. 1. Functional diagram of the information model ASM ITS CTS

On the basis of the approved regulations and in accordance with the job duties of the system coordinators and the range of tasks solved by the system users, the following basic access rights are provided for each automated workplace:

- the system user's workplace, ensures the submission of an electronic application form for cargo transportation, ranking of the transport infrastructure involved in order to ensure its suitability for contrailer shipments, calculation of the cost of transportation and the term of cargo delivery, obtaining information on the current state of the transport and production process (in the form of a schedule of loading and unloading operations) and information on following the road train;

- working place of the system administrator, provides control over submission of 
electronic application for transportation, adjustment of submitted electronic application for transportation, control over ranking of transport infrastructure, control over calculation of transportation cost and term of cargo delivery, input of information data on change or addition of electronic normative-reference documentation.

Based on the incoming information of the system users there is, among other things, the formation of a common database, as well as the accumulation of information in the database about the requested selection parameters and the requested recommendations[8]. The software is installed on the server, so there is no need to place other (additional) software on the user's stations.

In the information model ASM ITS CTS transport virtual cognitive system, is the main part (key element) that integrates other transport subsystems, while ensuring the intellectuality of transport space and as a result has a major impact on the process of choosing the optimal management solution. Stratified representation of the ASM ITS CTS transport virtual cognitive system is shown in figure 2.

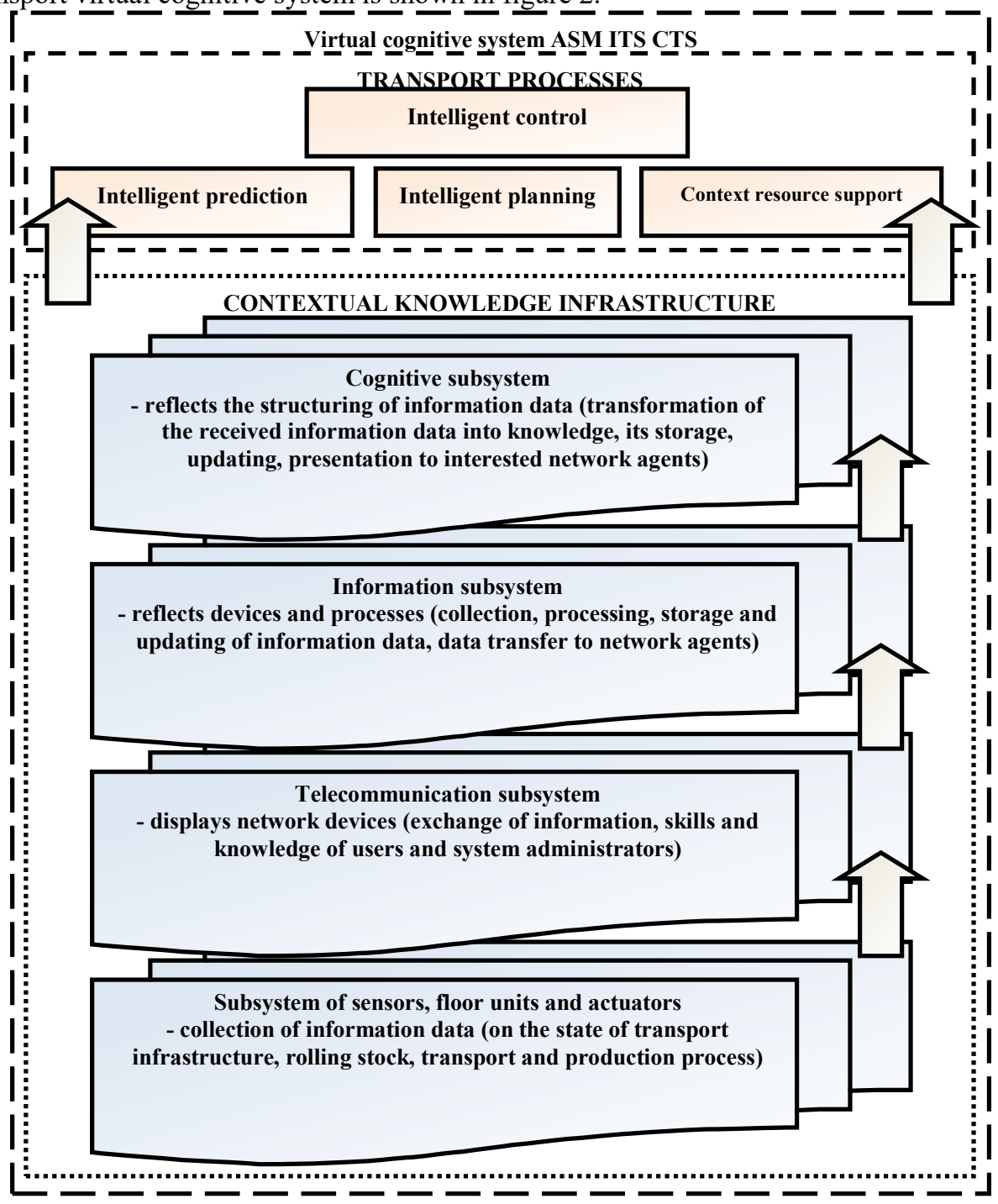

Fig. 2. Stratified representation of ASM ITS CTS transport virtual cognitive system 
As can be seen in Fig. 2:

- the bottom page, displays a subsystem of users of the system (including terminals and loading and unloading devices used in piggyback transport), as well as installed sensors on the rolling stock, sensors on the devices of the transport infrastructure and executive devices that collect information (on the current state, both transport infrastructure, rolling stock, and transport and production processes) and data on the implementation of organizational impacts;

- stratum of the telecommunication subsystem, reflects devices directly in the network, which provide complete and high-quality, specialized and reliable interaction in the exchange of information data on counter-release shipments, skills and knowledge of users and system administrators;

- The information subsystem page represents devices and processes that ensure information collection and control over the counterflow trains on the railway transport infrastructure, reflects the functions of accounting and recording the impact of transport subjects on the observance of the technological process at all its life cycles;

- stratum of cognitive subsystem, allows to transform and structure the processes of monitoring, analysis, accounting and storage of correspondence of the transport infrastructure of the proposed production facilities, railway stations and loading and unloading sites for their compliance with the requirements for the organization of correspondence of piggyback traffic;

- $\quad$ stratum of the applied subsystem, reflects the process of applying structured knowledge of monitoring, making optimal decisions, formation of management teams.

The difference of the virtual control system is in the intellectual architecture, namely the cognitive subsystem, which forms knowledge about the unified information system and operational and technological management on the basis of the above mentioned information data. Knowledge is formed on the basis of the results of processing of system state data coming from system agents and integrators[9].

ASM ITS CTS virtual cognitive system is implemented in programming languages JavaScript, Java, html, DB2, postgreSQL. Realizes its functionality on IBM PC-compatible personal computers, in the operating environment (compatible) Windows 7,8,10. Occupies volume of 15728000 bytes.

\section{Results}

The results of the ASM ITS CTS information model are formed by a software product, a set of regulatory and technical documentation, instructions for the system administrator and user, as well as the required set of methodological materials for the system implementation and use[10].

The information model visualization includes the following digital layers:

- Ranking of the involved transport infrastructure for compliance with the requirements for the organization of correspondences of piggyback transport (input of technical and technological data by the system user);

- the result of evaluation of the transport infrastructure on the basis of its ranking (the evaluation is performed by the system with assignment of rank from 1 to 5 and issuance of recommendations to the user on the necessary technical upgrading of production facilities or the conclusion that the facility is ready for the implementation of piggyback shipment);

- an electronic application form for piggyback transport;

- control over the current status of the consignments (performed through a search command by the assigned application number); 
- graph of the current state of the transport and production process (loading and unloading operations) carried out with road trains subject to restrictions;

- a list of normative-technical and regulatory documents regulating the organization and management of piggyback shipment.

Examples of ASM ITS CTS model visualization are presented in Figures 3, 4, 5, 6.

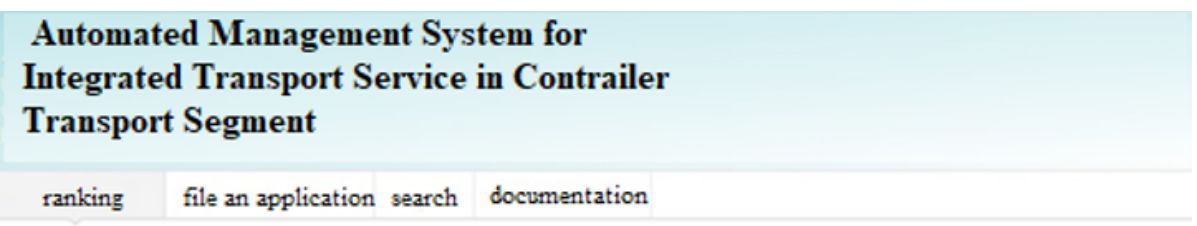

\section{Transport terminal}

selection parameter name
Possibility to receive, form and send train routes (set in the direction of weight
and length)
Possibility to process the additional loading/unloading volume involved
Ability to feed/clean the entire route of the journey (optimal)
Quantity of cars in feed / stripping, track profiles, the ability to produce
maneuvers and routes, etc.
Loading and unloading fronts (length, loading and unloading facilities), feeder
and pick-vp tracks, exhibition venves (capacity)

Fig. 3. A fragment of the digital layer of the transport infrastructure ranking supposed to be used for the organization of counterflow shipments

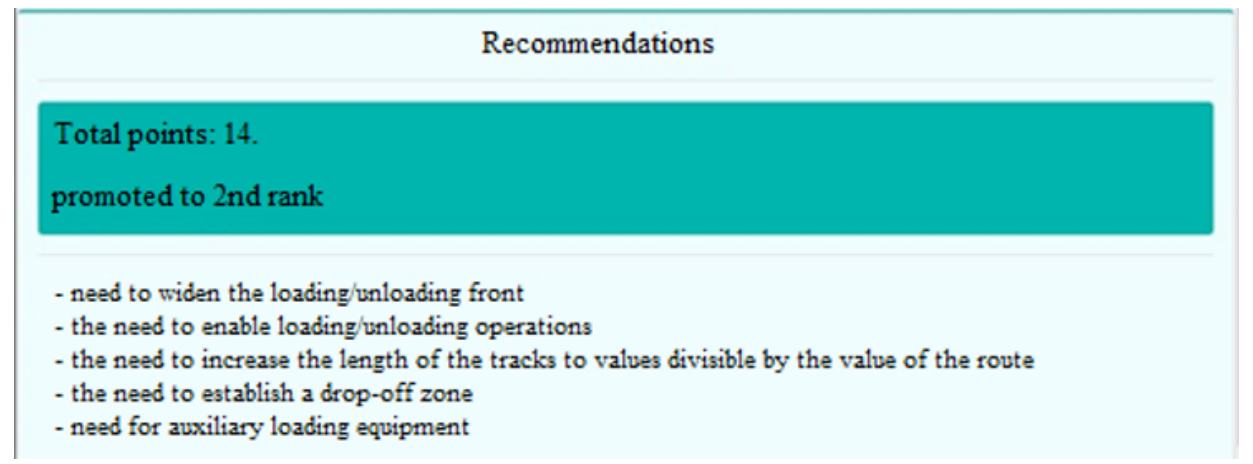

Fig. 4. A fragment of the digital layer of transport infrastructure assessment results and a list of recommendations 


\section{Automated Management System for Integrated Transport Service in Contrailer Transport Segment}

ranking file an application searc documentation

Fig. 5. A fragment of the digital search layer by the application number of the current state of the piggyback shipment

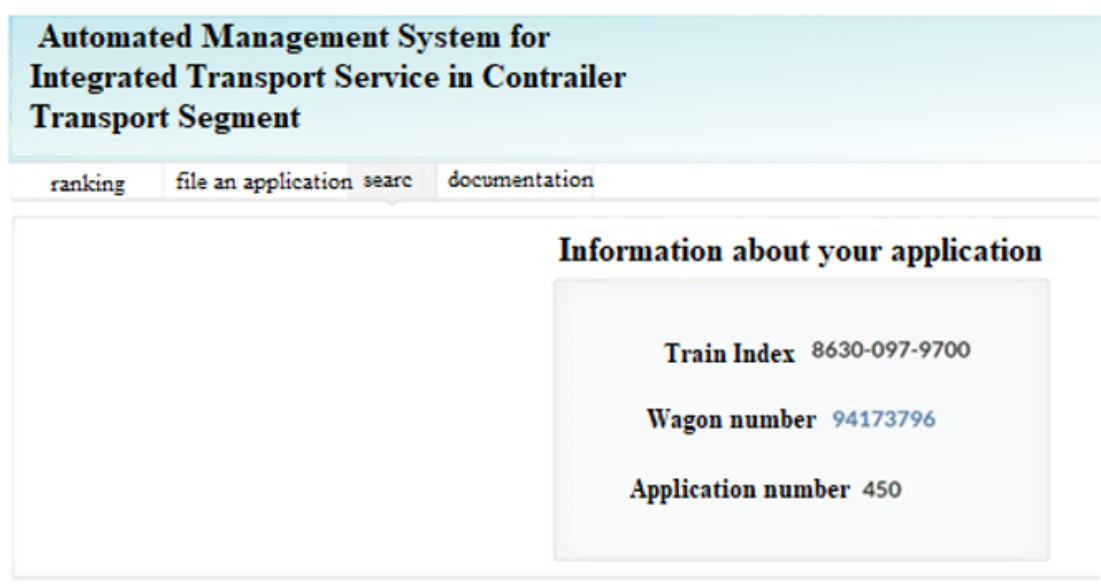

Fig. 6. A fragment of the digital layer of code information output on the current state of the piggyback sending

Thus, the presented information model of ASM ITS CTS creates conditions for unification of information data of network users, and also data of other information networks functioning in the uniform transport and information space (as agreed) that fills it with the necessary information stream providing self-support and self-adaptation of transport and production process of the organization and management of piggyback transportation[11].

The ASM ITS CTS information model is registered by the Federal Service for Intellectual Property of the Russian Federation.

\section{Discussion}

The ASM ITS CTS model is multi-agent, provides users with a virtual platform that includes many interested parties of contrailer transportation correspondence:

- to perform the procedure of ranking of the involved transport infrastructure with regard to the suitability for the organization of piggyback transportation, at the same time it displays an electronic form with the fields of information data entry about the object name and the evaluation (rank) and provides an automated calculation of points with the issuance of recommendations[12]; 
- to execute an electronic application for a counter-translair shipment, in this case it displays a dialog form with fields for entering the transportation criteria;

- help in filling out the shipping criteria in the form of a tooltip pop-up list in the information input fields;

- information on the results of registration of the application with the assignment of the electronic application number and the preliminary (planned) rolling stock number;

- calculation of the cost of cargo delivery by specified parameters;

- information about the normative, actual delivery time of the cargo in this case, in case of non-fulfillment of the normative delivery time, provides the reason for nonfulfillment of the established term and the guilty subject[13];

- track information about the current status of shipments, view the schedule of the transport and production process, with the system gives information in the form of a message about the discrepancies, determines and red on the schedule shows failure to comply with standards of technical operations;

- access to electronic normative-technical and normative-legal documents used in the implementation of counter-transit transport[14].

- The ASM ITS CTS model provides the system administrator:

- access to information flows for data exchange and control when making transport requests;

- access to electronic data forms during the process of supplementing (adjusting) regulatory and reference information;

- access to electronic data forms during control of transport selection parameters and recommendations processing;

- $\quad$ access to the electronic forms of the normative schedule of piggyback consignments and the transport and production process when making their updated normative data[15].

Parameters of the carried out calculations define, that using the given information model, conditions for exception of the non-productive periods in the field of interaction of types of transport at the organization of counterflow transportations are created and the uniform transport-production process that finally leads to decrease in the cost price of the given type of transportation is formed.

\section{Conclusions}

The developed model has basic features that distinguish it from other information models, such as:

- accounting and registration of the impact of the subjects of carriage on the implementation of the graphical standard of contrailer road trains;

- accounting and registration of the impact of the subjects of carriage on the performance of the graphic standard of the transport and production process;

- $\quad$ processing, recognition and consolidation of information flows of different systems;

- integration into other information systems used in the common transport and information space (as agreed);

- availability of a cognitive subsystem that forms knowledge about a single information system and operational and technological management.

These basic features characterize the model as qualitatively new from those, which are used in management of transport and logistic processes.

Application of information model ASM ITS CTS creates conditions for development of through transport and production processes, formation of a single technology of delivery of goods by contrailer shipments, assuming the continuity of the cargo transportation process 
at all its stages. It ensures well-coordinated operation of road and rail transport. Facilitates the development of the railway industry potential in the field of interaction of several modes of transport, integration of the Russian transport system into the world transport and information space and improvement of the transit potential of the country.

\section{References}

1. S. Treber, R. Breig, M. Kentner, B. Hafner. Procedia CIRP. 84. 225-230 (2019). doi: 10.1016/j.procir.2019.04.214

2. P. Leviakangas Technology in Society. 47. 1-15 (2016). doi: 10.1016/j.techsoc.2016.07.001

3. Hai Wang, Hai Yang. Transportation Research. Part B. 129, 122-155 (2019). doi: 10.1016/j.trb.2019.07.009

4. T. Ramadhan, D. Wibisono, R.A. Nasution, S. Novani. Procedia Manufacturing, 4, 402-411 (2015). doi: 10.1016/j.promfg.2015.11.056

5. A. Jarašūnienè, G. Sinkevičius, A. Mikalauskaitè. Procedia Engineering, 187, 173-184 (2017). doi: 10.1016/j.proeng.2017.04.363

6. Z. He, L. Rayman-Bacchus, Y. Wu. Research Policy, 40, 1280-1294 (2011). doi: 10.1016/j.respol.2011.07.008

7. Y. Li, F. Wu. Progress in Planning, 78, 55-99 (2012). doi: 10.1016/j.progress.2012.03.001

8. Gerhard S., Lukas S. Use of ITS technologies for multimodal transport operations River Information Services (RIS) transport logistics services. Procedia - Social and Behavioral Sciences 48 (2012), pp 622-630. doi: 10.1016/j.sbspro.2012.06.1040

9. J. Wang. Journal of Parallel and Distributed Computing, 66(5), 750-762 (2006). doi: 10.1016/j.jpdc.2005.12.003

10. L. Zhang, J. K. Muppala, S.T. Chanson. Journal of Parallel and Distributed Computing, .66(3), 367-378 (2006). doi: 10.1016/j.jpdc.2005.08.003

11. V. Lo. Advances in Computers, 39, 191-237 (1994). doi: 10.1016/S00652458(08)60380-0

12. D.P. Pezaros, K. Georgopoulos, D. Hutchison. Computer Networks, 54 (18), 32463263 (2010). doi: 10.1016/j.comnet.2010.06.014

13. G.C. Hadjichristofi, L.A. DaSilva, S.F. Midkiff, U. Lee, W. De Sousa. Computer Networks, 55(1), 282-299 (2011). doi: 10.1016/j.comnet.2010.09.001

14. V. Kalogeraki, D. Zeinalipour-Yazti, D. Gunopulos, A. Delis. Journal of Network and Computer Applications, 30 (1), 209-243 (2007). doi: 10.1016/j.jnca.2005.09.001

15. Q. Li, D. Ming Chiu, M. Xu, J. Wu. Performance Evaluation, 71, 25-43 (2014). doi: 10.1016/j.peva.2103.09.004 